\title{
Synthesis and secretion of transferrin by a bovine trabecular meshwork cell line
}

\section{R. Bertazolli-Filho, \\ E.M. Laicine and A. Haddad}

\author{
Departamento de Biologia Celular e Molecular e Bioagentes Patogênicos, \\ Faculdade de Medicina de Ribeirão Preto, Universidade de São Paulo, \\ Ribeirão Preto, SP, Brasil
}

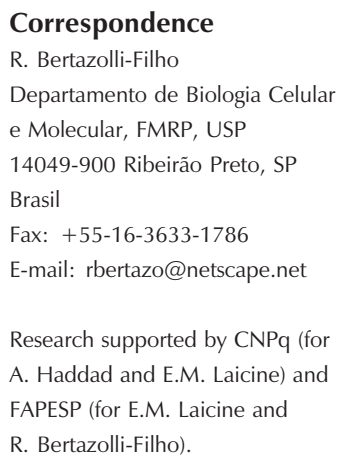

\begin{abstract}
The trabecular meshwork (TM) is the main outflow pathway in the mammalian eye. Oxidative damage to TM cells has been suggested to be an important cause of impairment of TM functions, leading to deficient drainage of aqueous humor, with deleterious consequences to the eye. Transferrin, a metalloprotein involved in iron transport, has been characterized as an intrinsic eye protein. Since transferrin is implicated in the control of oxidative stress, the objective of the present study was to determine if a bovine TM cell line (CTOB) synthesizes and secretes transferrin. The CTOB cell line was cultured in the presence of ${ }^{35} \mathrm{~S}$-methionine and the incubation medium was submitted to immunoprecipitation. Total RNAs from CTOB and isolated bovine TM (freshly isolated, incubated or not) were subjected to the reverse transcription-polymerase chain reaction and the amplification products were sequenced. Also, both CTOB and histological TM preparations were processed for transferrin immunolocalization. A labeled peptide of about $80 \mathrm{kDa}$, the expected size for transferrin, was immunopurified from CTOB samples obtained from the incubation assays. The reverse transcription-polymerase chain reaction and sequencing experiments detected the presence of transferrin mRNA in CTOB and isolated bovine TM. Reactivity to antibodies against transferrin was observed both in CTOB and TM. The results obtained in all of these experiments indicated that the TM is capable of synthesizing and secreting transferrin. The possible implications for the physiology of the eye are discussed.
\end{abstract}

\section{Introduction}

The trabecular meshwork (TM), located at the angle of the anterior chamber, plays a role in the drainage of the aqueous humor $(\mathrm{AH})$ of the anterior chamber, both in the eyes of primates (which also exhibit the Schlemm canal) and of non-primate mammals (1). After circulating through the TM,
Key words

- Bovine eye

- Trabecular meshwork

- Transferrin expression

- Cell and tissue culture

- Immunocytochemistry 
spur and uvea. Damage to the TM can reduce the drainage of AH outflow, ultimately leading to an increase of intraocular pressure, the major causal risk factor of glaucoma (2).

Transferrin is an $80-\mathrm{kDa}$ metalloprotein which is the major iron transporter glycoprotein in plasma (3). Even though the main source of transferrin in the body is the liver, many extra-hepatic sources exist. Several eye sites are capable of synthesizing and secreting transferrin, including the retina (4), lens (5) and ciliary epithelium (6). Both the lens and the ciliary epithelium face the posterior chamber, which means that the secreted transferrin becomes a constituent of the $\mathrm{AH}$. The presence of transferrin in $\mathrm{AH}$ as apotransferrin (iron-free) could be important in preventing the generation of free radicals since it could remove the free iron molecules in the AH. In the past few years, several investigations have indicated that oxidative stress is a possible cause of damage to the trabecular meshwork, impairing its functions in AH outflow (7). Since transferrin has a potential protective effect against the free radicals present in the $\mathrm{AH}$, it is of interest to investigate the ability of CTOB, a bovine TM cell line, to synthesize and secrete transferrin.

\section{Material and Methods}

\section{Cell culture}

TM was obtained from a steer (Bostaurus) at a local slaughterhouse. Trabeculotomy was performed as follows: the enucleated eyes were washed in sterile PBS $(137 \mathrm{mM}$ $\mathrm{NaCl}, 2 \mathrm{mM} \mathrm{KCl}, 0.9 \mathrm{mM} \mathrm{CaCl}_{2}, 1.54 \mathrm{mM}$ $\mathrm{MgCl}_{2}, 6.5 \mathrm{mM} \mathrm{Na}_{2} \mathrm{HPO}_{4}, 1.47 \mathrm{mM} \mathrm{KH}_{2} \mathrm{PO}_{4}$, $\mathrm{pH}$ 7.2) and the posterior portion of each eye was removed; the anterior portions were either processed for immunohistochemistry (see below) or had their ciliary body-iris detached. Bovine TM was dissected under a surgical microscope by an ophthalmic sur- geon with expertise in trabeculotomy. Once it was confirmed that the TM was free from any surrounding tissue, TM fragments were chopped into very small pieces, which were used for the primary cultures. Alternatively, other fragments were digested with trypsinEDTA solution to obtain free cells. Both the small pieces and the TM-free cells were plated onto flasks (Corning, New York, NY, USA) containing Dulbecco's modified Eagle's medium (DMEM, Gibco, Grand Island, NY, USA), supplemented with $10 \%$ fetal calf serum (Gibco) in a humidified incubator under a $5 \% \mathrm{CO}_{2}$-air atmosphere at $37^{\circ} \mathrm{C}$ until reaching confluence. Three successful cell cultures were obtained and frozen after 7 to 10 passages. One of these cultures has been continuously replicated more than 200 times. Several tests have been carried out to check the origin of the cells and their ability to phagocytize the protein of the crystalline. Additionally, TM fragments were cultured as explants in a chamber of a Transwell ${ }^{\circledR} 6 \mathrm{MM}$ plate (Costar, New York, NY, USA) filled with $1 \mathrm{~mL}$ serumfree DMEM for $24 \mathrm{~h}$, with at least 3 medium changes during incubation before RNA extraction and immunocytochemistry processing.

\section{Reverse transcription-polymerase chain reaction assays}

The culture medium was removed and the CTOB cells were washed several times with cold PBS. RNA was isolated with Trizol (Gibco) according to manufacturer instructions. The RNA from the TM explants was obtained in the same way. To avoid possible genomic DNA contamination in the reverse transcription (RT) preparation, RNA samples were pretreated with DNase (Promega, Madison, WI, USA) before RT, as suggested by the manufacturer. The synthesis of the firststrand complementary DNA (RT) was performed with 1 (TM explants) or $5 \mu \mathrm{g}$ (CTOB) total RNA, using SuperScript ${ }^{\mathrm{TM}}$ (Gibco) as 
indicated by the manufacturer. The oligonucleotide set of primers used in PCR amplification and sequencing were synthesized by Imprint. The set of primers (upper-tgtta gcctgcgcggttctgg 23-43; lower-gacatttaaa ggcccctgagtagc 628-652) was designed in the expectation that it would span at least one intron, permitting the detection of possible genomic contamination. Primers were chosen on the basis of published bovine liver transferrin cDNA nucleotide sequences (NM_177484) and were selected using the DNASTAR program (DNASTAR Inc., Madison, WI, USA, licensed to Hemocentro de Ribeirão Preto). cDNA was amplified by polymerase chain reaction using $5 \mu \mathrm{L}$ of the products from RT, $25 \mathrm{pmol}$ of each primer, $50 \mu \mathrm{L}$ of reaction buffer, $1 \mathrm{mM}$ of dNTP mixture, and $0.5 \mu \mathrm{L}$ of Taq polymerase (Gibco $2.5 \mathrm{U} / \mu \mathrm{L}$ ) in a final volume of $50 \mu \mathrm{L}$. A thermal cycler $\left(\right.$ GeneAmp ${ }^{\circledR}$ PCR System 9700, PE Applied Biosystems, Foster City, CA, USA) was used with the following temperature profiles: initial melting at $94^{\circ} \mathrm{C}$ for 2 min, 321 -min melting cycles at $94^{\circ} \mathrm{C}, 1$ min annealing at $58^{\circ} \mathrm{C}$, and 1 min extension at $72^{\circ} \mathrm{C}$. After the last cycle, polymerization was extended for $10 \mathrm{~min}$, when the chains were complete. The products of amplification $(10 \mu \mathrm{L})$ were analyzed on $1.2 \%$ agarose gels and the amplified bands were gel-purified using the GFX ${ }^{\mathrm{TM}}$ kit (Pharmacia, Little Chalfont, Buchinghamshire, UK).

\section{Nucleotide sequencing}

PCR DNA products were sequenced on both strands using the automated DNA sequencer ABI PRISM 377 Genetic Analyzer (Foster City, CA, USA) and the BigDye Rhodamine Terminator Cycle sequencing kit (PE Applied Biosystems), at the Hemocentro of Ribeirão Preto facilities.

\section{Isotopic labeling experiments}

For the isotopic labeling experiments the semi-confluent cells, grown in a $25-\mathrm{cm}^{2}$ flask, were washed several times in sterile PBS and $2 \mathrm{~mL}$ DMEM without methionine plus $25 \mu \mathrm{Ci}{ }^{35} \mathrm{~S}$-methionine (Amersham, Little Chalfont, Buckinghamshire, UK), specific activity $>800 \mathrm{Ci} / \mathrm{mmol}$, were then added to each flask. The preparations were incubated for $24 \mathrm{~h}$, the media were recovered, precleared by centrifugation at $16,000 \mathrm{~g}$ for 30 min at $4^{\circ} \mathrm{C}$, and submitted to immunoprecipitation.

\section{Immunoprecipitation and SDS-PAGE analysis}

The media resulting from the incubation of CTOB cells were immunoprecipitated using $5 \mu \mathrm{L}$ of goat anti-rabbit transferrin antibody (Cappel ICN Pharmaceuticals Inc., Aurora, $\mathrm{OH}, \mathrm{USA}$ ) plus protein A bound to Sepharose CL4B, as described (8). After immunoprecipitation, the samples were analyzed by $10 \%$ SDS-PAGE under reducing conditions (9) plus fluorography (10). After SDS-PAGE, the gels were stained with Coomassie brilliant blue R-250, photographed, impregnated with Amplify ${ }^{\mathrm{TM}}$ (Amersham), dried under vacuum and exposed to $\mathrm{X}$ OMAT-AR5 film (Kodak, Rochester, NY, USA) for different times at $-80^{\circ} \mathrm{C}$.

\section{Immunocytochemistry}

For immunocytochemical analysis, CTOB cells were grown on fibronectintreated coverslips inside a Costar 6MM transwell micro-well plate. When they had reached semi-confluence, the cells were washed several times in sterile PBS and grown in serum-free DMEM for $24 \mathrm{~h}$ with at least three changes of fresh medium. After this step, the cells were fixed in $10 \%$ formalin in $0.1 \mathrm{M}$ Sorensen's buffer for $15 \mathrm{~min}$ at $37^{\circ} \mathrm{C}$, washed several times with $0.1 \mathrm{M}$ Sorensen's buffer, $\mathrm{pH} 7.2$, incubated in $0.1 \mathrm{M}$ glycine for 30 min, rewashed in TTBS $(50 \mathrm{mM}$ Tris, $\mathrm{pH}$ 7.2, $0.1 \%$ Triton X-100), and blocked with $2 \%$ BSA in TTBS for $1 \mathrm{~h}$. The cells were 
incubated with the first antibody (goat antirabbit transferrin; Cappel) diluted 1:200 in blocking buffer for $2 \mathrm{~h}$ at room temperature. The coverslips were rinsed in TTBS and incubated with the secondary antibody, rhodamine-conjugated anti-goat $\operatorname{IgG}$, diluted 1:200, for $1 \mathrm{~h}$ at room temperature. After washing in TTBS and mounting in a solution of Fluoromount ${ }^{\mathrm{TM}}$ (Southern Biotechnology Associated, Inc., Birmingham, AL, USA) medium, the cells were analyzed with a Confocal microscope (Leica TCS NT, Wetzlar, Germany) coupled to an inverted DM IRBE Leica microscope. The images were captured using a Fuji Pictrography 3000 printer (Tokyo, Japan) connected to the confocal device. The controls were run either omitting the primary antibody or using the nonimmune goat serum. The anterior portion of the eye and the explants of isolated and incubated TM were fixed in $10 \%$ formalin in $0.1 \mathrm{M}$ Sorensen's buffer for $24 \mathrm{~h}$ at $4^{\circ} \mathrm{C}$, embedded in paraffin and cut into $6-\mu \mathrm{m}$ thick sections. The immunohistochemical reactions were performed as described for the CTOB, except that it was used the Vectastain ABC Kit (Anti-goat IgG, Vector, Burlingame, CA, USA) to detect the primary antibody. The specimens were examined with

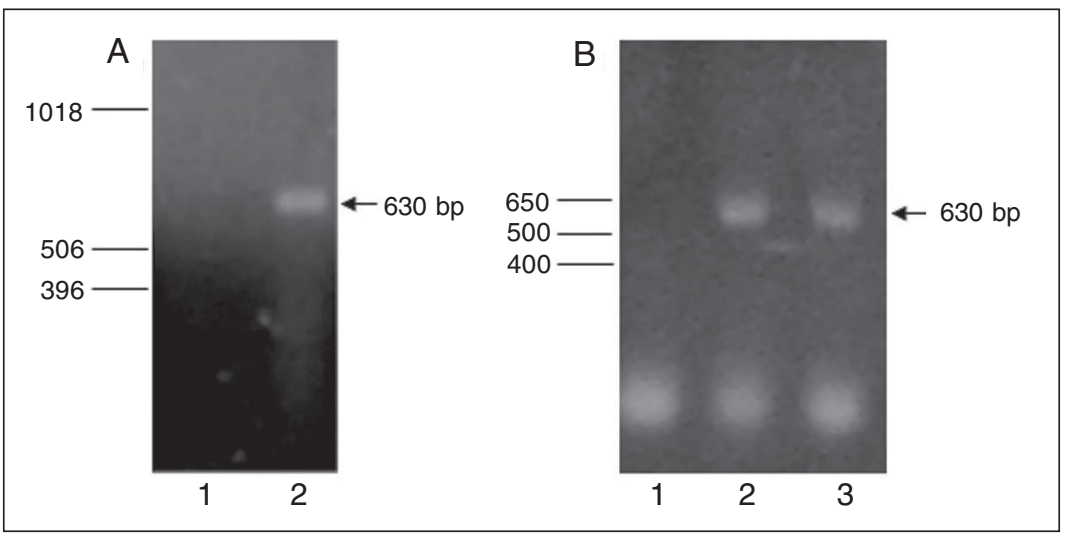

Figure 1. RT-PCR of transferring. $A, 1$ ) Negative control (water), 2) CTOB, a bovine trabecular meshwork cell line. $B, 1$ ) Negative control (water), 2) isolated bovine trabecular meshwork, 3) bovine 21-h incubated trabecular meshwork explant. Samples of $10 \mu \mathrm{L}$ were analyzed on $1.2 \%$ agarose gels. The arrows point at the amplification products with the expected length (630 bp). Molecular weight markers are at left: $1 \mathrm{~kb}$ Ladder (A) and $1 \mathrm{~kb}$ Ladder Plus (B) (Gibco). an Axiophot microscope (Zeiss, Oberkochen, Germany) and the images captured with a CCD-IRIS camera (Sony, Tokyo, Japan) and digitized (Snappy 3.0, Play Inc., London, UK).

\section{Results}

Expression of transferrin mRNA in the CTOB cell line and isolated trabecular meshwork

The RT-polymerase chain reaction was used to detect the expression of transferrin mRNA both in the CTOB cell line and isolated TM before and after incubation. Based on the known transferrin gene structures (e.g., human and rabbit ones), the primer sets used in our experiments were expected to cover the region of the transferrin message spanning exons 2 to 6 .

Figure 1A shows the representative amplifications of the transferrin message from CTOB. Figure 1B shows a representative amplification of the transferrin message from freshly isolated TM (2) and from TM incubated for $21 \mathrm{~h} \mathrm{(3).} \mathrm{The} \mathrm{amplification} \mathrm{prod-}$ ucts were of expected size and the sequence analysis of the amplified products indicated $100 \%$ homology with the published transferrin sequence(NM-177484). These experiments indicate that both the CTOB cell line and the isolated TM express transferrin mRNA.

\section{Immunoprecipitation assays}

The incubation experiments using the CTOB cell line followed by immunoprecipitation with the specific antiserum against rabbit transferrin were performed to determine the ability of CTOB to synthesize and secrete transferrin into the culture medium. Figure 2 shows a representative immunoprecipitation experiment of the isotopically labeled transferrin from the CTOB culture media. Fluorography revealed a band of about $80 \mathrm{kDa}$, corresponding to the expected size of transferrin. 


\section{Immunohistochemistry}

The specific antibody against transferrin was used in an indirect immunofluorescence assay to examine the cellular distribution of transferrin in the CTOB cell line. The samples were analyzed using confocal microscopy.

Figure 3 shows a representative labeling pattern of transferrin antigenicity in a CTOB cell. Antigenicity was detected throughout the cytoplasm.

A similar labeling pattern was observed in intact (Figure 4A) and incubated TM (Figure 4B), with diffuse staining of trabecular cells. A slight swelling of the trabeculae can be seen in Figure 4B compared with intact TM (Figure 4A).

\section{Discussion}

We report here the expression of the metalloprotein transferrin based on mRNA and protein analysis by CTOB, a cell line derived from bovine TM. The expression of transferrin mRNA was analyzed both in the cell line and in isolated tissue, incubated or not. Trabecular cell lines are extensively used in studies of TM function since it is difficult to obtain large amounts of TM samples. However, as in any in vitro analysis, it is important to check whether cell line expression reflects the phenotype of the intact tissue or if it is a spurious modification of the secretion pattern due to incubation conditions. There are reports indicating that a tissue in culture may not behave as it does in its proper environment in a living animal. This is the case for TM concerning the expression of several genes which are expressed in vivo but not in vitro and vice versa (for a comprehensive review, see Ref. 11). The existence of an intrinsic vitreous transferrin has been demonstrated (12) and many studies were subsequently carried out to determine its origins. Many eye components have been considered to be potential sources of vitreous transferrin, including the retina (4), lens (5) and ciliary epithelium (6). Regarding the aqueous humor, the intrinsic transferrin could reach it either by migration from the vitreous and/or by secretion from the lens and ciliary epithelium. The migration of vitreous protein to the aqueous humor has been demonstrated (13).

Transferrin has the ability to rapidly bind $\mathrm{Fe}$ (III) from the eye humors, matrices and extracellular fluids. The expression of transferrin in the outflow system can be important to prevent the generation of free radicals through the Fenton reaction since low-molecular weight iron can act as a catalyst to
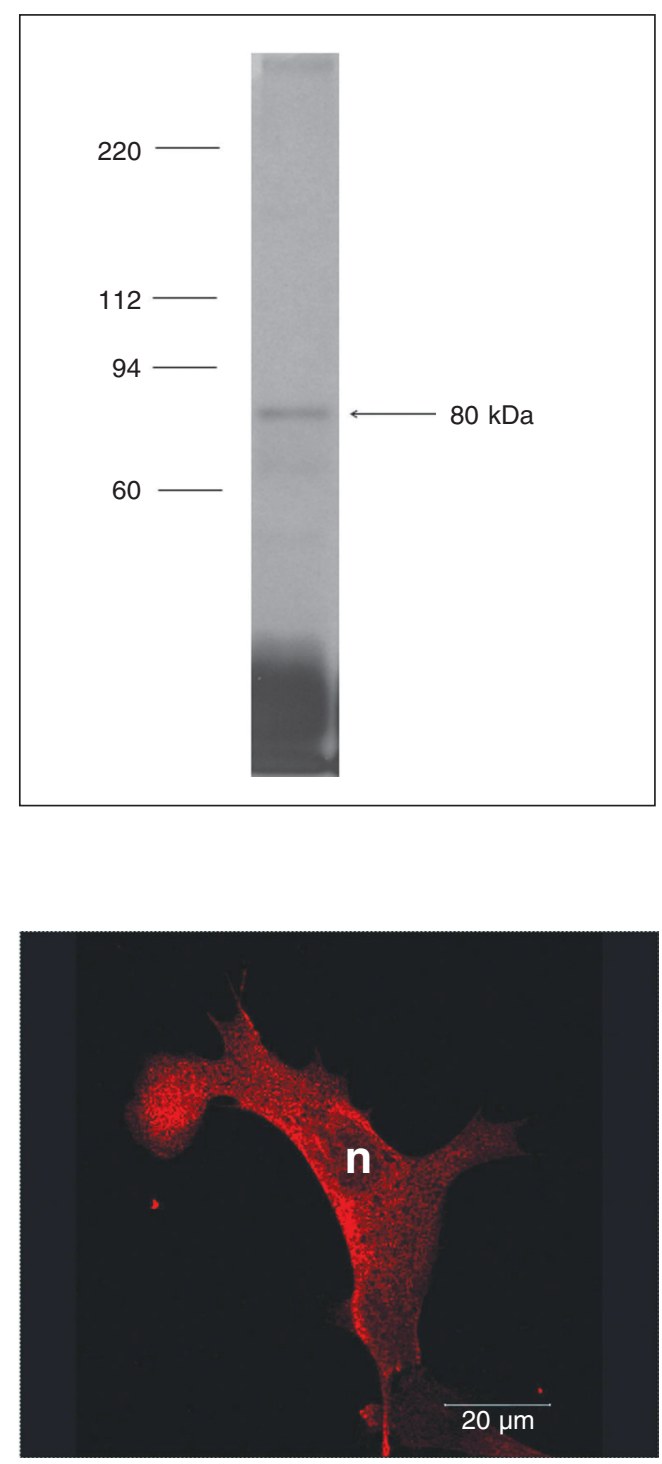

Figure 2. SDS-PAGE plus fluorography of the transferrin. The labeled fraction present in the extracts of CTOB (bovine trabecular meshwork cell line) culture medium was immunoprecipitated after incubation for 24 $\mathrm{h}$ in methionine-free DMEM containing $25 \mu \mathrm{Ci}$ 35S-methionine. The immunoprecipitation was carried out using antitransferrin antibody plus protein $A$ bound to Sepharose CL4B and the resulting immunoprecipitated sample was processed for SDS-PAGE plus fluorography on $10 \%$ polyacrylamide gel. The arrow indicates the transferrin band. Molecular weight markers are at left. 
potentiate oxygen toxicity by the generation of a wide range of free radical species, including hydroxyl radicals, the most reactive of the free radicals, which have the ability to react with a wide range of cellular components. The deleterious effects of iron in the vitreous have been demonstrated (14). Since the aqueous humor has a high concentration of hydrogen peroxide (15), it is of particular importance to remove any free transition metal present in it.

It has been shown that oxidative stress

Figure 4. Tissue distribution of transferring on $6-\mu \mathrm{m}$ paraffin sections. Immunolabeling of the intact (in situ) bovine trabecular meshwork (A) and cultured trabecular meshwork explant (B). The positive reaction is visible on the trabecular cells and surrounding thick matrix sections (arrows). The control (primary antibody omission) was negative (not shown). The reactions were developed with DAB and $0.003 \%$ hydrogen peroxide using the Vectastain $A B C$ kit (Vector). No counterstaining. Bar = $10 \mu \mathrm{m}$.
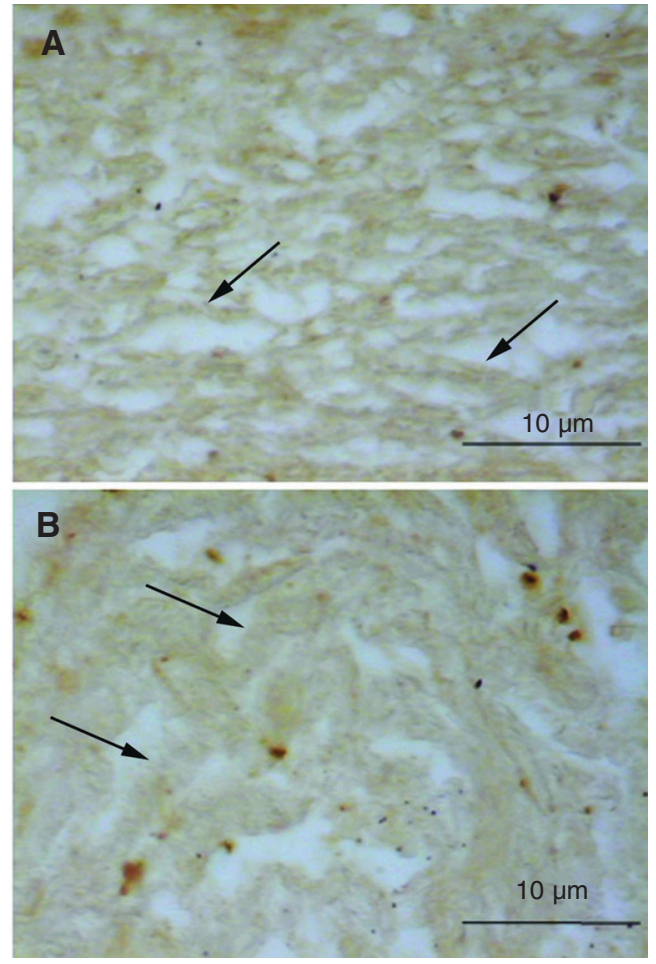

affects the morphology and physiology of the outflow pathway in aging as well as in glaucoma (16). Also, it has a negative effect on the TM cell adhesiveness and leads to a cytoskeleton rearrangement in addition to NF- $\mathrm{KB}$ activation (17). NF- $\kappa B$ was the first transcriptional factor shown to respond directly to oxidative stress. In fact, it was demonstrated that glaucomatous TM expresses selectin-E by the activation of NF-kB and selectin- $\mathrm{E}$ is considered to be the first phenotype marker for glaucoma (18). The proteasoma of TM cells submitted to chronic oxidative stress is inhibited (19) and the oxidative DNA damage in the patients with glaucoma is significantly higher than in controls (20).

Inside the eye, apotransferrin has proven to be effective in the prevention of some inflammatory conditions $(21,22)$, possibly acting synergistically with other antioxidants present in the eye (15). Keeping the aqueous humor free of the transition metals is probably important for the long-term maintenance of homeostasis of TM, preventing the excessive generation of free radicals constantly related to aging and degenerating disease (23).

\section{Acknowledgments}

We are grateful to Vani M.A. Correa and Domingos S. de Souza-Filho for technical help. We also wish to thank Dr. Ryoko Chokiu (Volta Redonda, RJ, Brazil) for her expert assistance with trabeculotomy.

\section{References}

1. Lutjen-Drecoll E. Functional morphology of the trabecular meshwork in primate eyes. Prog Retin Eye Res 1999; 18: 91-119.

2. Kass MA, Heuer DK, Higginbotham EJ, Johnson CA, Keltner JL, Miller JP, et al. The Ocular Hypertension Treatment Study: a randomized trial determines that topical ocular hypotensive medication delays or prevents the onset of primary open-angle glaucoma. Arch Ophthalmol 2002; 120: 701-713 (discussion 829-830).

3. de Jong G, van Dijk JP, van Eijk HG. The biology of transferrin. Clin Chim Acta 1990; 190: 1-46.

4. Davis AA, Hunt RC. Transferrin is made and bound by photorecep- tor cells. J Cell Physiol 1993; 156: 280-285.

5. McGahan MC, Harned J, Goralska M, Sherry B, Fleisher LN. Transferrin secretion by lens epithelial cells in culture. Exp Eye Res 1995; 60: 667-673.

6. Bertazolli-Filho R, Laicine EM, Haddad A. Synthesis and secretion of transferrin by isolated ciliary epithelium of rabbit. Biochem Biophys Res Commun 2003; 305: 820-825.

7. Babizhayev MA, Bunin AY. Lipid peroxidation in open-angle glaucoma. Acta Ophthalmol 1989; 67: 371-377.

8. Rosenberg IM. Protein analysis and purification: Benchtop tech- 
niques. Boston: Birkhäuser; 1996.

9. Laemmli UK. Cleavage of structural proteins during the assembly of the head of bacteriophage T4. Nature 1970; 227: 680-685.

10. Waterborg JH, Matthews HR. Fluorography of polyacrylamide gels containing tritium. In: Walker JM (Editor), Methods in molecular biology proteins. Clifton: Humana Press; 1984. p 147-152.

11. Borrás T. Gene expression in the trabecular meshwork and the influence of intraocular pressure. Prog Retin Eye Res 2003; 22: 435463.

12. Laicine EM, Haddad A. Transferrin, one of the major vitreous proteins, is produced within the eye. Exp Eye Res 1994; 59: 441-445.

13. Haddad A, Laicine EM, de Almeida JC. Origin and renewal of the intrinsic glycoproteins of the aqueous humor. Graefes Arch Clin Exp Ophthalmol 1991; 229: 371-379.

14. Hui YN, Sorgente N, Ryan SJ. Liquefaction of rabbit vitreous by ferrous ions. Curr Eye Res 1988; 7: 655-660.

15. Rose RC, Richer SP, Bode AM. Ocular oxidants and antioxidant protection. Proc Soc Exp Biol Med 1998; 217: 397-407.

16. Green K. Free radicals and aging of anterior segment tissues of the eye: a hypothesis. Ophthalmic Res 1995; 27 (Suppl 1): 143-149.

17. Zhou L, Li Y, Yue BY. Oxidative stress affects cytoskeletal structure and cell-matrix interactions in cells from an ocular tissue: the trabecular meshwork. J Cell Physiol 1999; 180: 182-189.

18. Wang N, Chintala SK, Fini ME, Schuman JS. Activation of a tissuespecific stress response in the aqueous outflow pathway of the eye defines the glaucoma disease phenotype. Nat Med 2001; 7: 304309.

19. Caballero M, Liton PB, Epstein DL, Gonzalez P. Proteasome inhibition by chronic oxidative stress in human trabecular meshwork cells. Biochem Biophys Res Commun 2003; 308: 346-352.

20. Izzotti A, Sacca SC, Cartiglia C, De Flora S. Oxidative deoxyribonucleic acid damage in the eyes of glaucoma patients. Am J Med 2003; 114: 638-646.

21. McGahan MC, Grimes AM, Fleisher LN. Hemoglobin exacerbates the ocular inflammatory response to endotoxin. Graefes Arch Clin Exp Ophthalmol 1996; 234: 643-647.

22. McGahan MC, Grimes AM, Fleisher LN. Transferrin inhibits the ocular inflammatory response. Exp Eye Res 1994; 58: 509-511.

23. Tezel G. Oxidative stress in glaucomatous neurodegeneration: mechanisms and consequences. Prog Retin Eye Res 2006; 25: 490-513. 